\title{
Dentinal variations after application of an adhesive containing isopropanol used in etch and rinse mode on moist and dried dentin
}

\author{
Geneviève Grégoire $^{1 *}$, Patrick Sharrock ${ }^{2}$ and Bruno Tavernier ${ }^{3}$ \\ ${ }^{1}$ Faculty of Odontology, University Toulouse III, Toulouse and University Paris Descartes, France \\ ${ }^{2}$ University Toulouse III, Toulouse, France \\ ${ }^{3}$ Faculty of Odontology, University Paris Diderot; Rothschild Hospital AP-HP, Paris, France
}

\begin{abstract}
The aim of this study was to compare the technique sensitivity of an adhesive system to the moisture conditions of the dentinal substrate by measuring the dentin permeability variation. Infrared spectroscopy allows analysis of dentin components and in particular the remaining dentin water, depending on application of the adhesive on dry or humid dentin. Thermal studies help determining whether the water is free or bound. Within the limitations of this study the adhesive didn't yield unfavourable results, whether the technique was moist or overdry. The results point to the use of isopropanol as a solvent with favourable solubilities and vapour pressure compatible with adhesive resins.
\end{abstract}

\section{Introduction}

The main problem with adhesive systems stems from mismatch between the degrees of surface humidities. Enamel must be dry and dentin moist but not soaked, which requires good knowledge of the indications and modes of action for different adhesive systems.

In fact, too much drying, or excess water could lead to loss of proper sealing and jeopardize adhesion [1]. Authors have shown that air-drying of etched dentin causes contraction and collapse of the unsupported layer of collagen, preventing resin monomers from wetting and infiltrating adequately the etched surface [2]. Conversely, excess water between interfibril spaces impedes resin infiltration and proper polymerization which provokes poor association between collagen and adhesive resin. With residual water present on collagen, the hydrophobic polymeric sections of resins may not interpenetrate with collagen peptides.

Too much water may cause phase separation in adhesive compositions leading to irregular infiltration with voids and bubbles at interfaces.

The function of primers is to humidify exposed collagen fibrils, eliminate residual water and transform hydrophilic surfaces to hydrophobic, letting enough resin penetration into interfibrillar spaces of demineralized dentin. This action is promoted by combination with a solvent helping water displacement from humid collagen structures [3]. Optimal surface humidity for binding depends on adhesive components including their solvents. Solvents can be water alcohol (ethanol, isopropanol...) and acetone. Thus, water based systems tolerate well dry dentin while acetone based systems need more humid dentin surfaces to reach high levels of bonding forces [1].

Solvents allow collagen, impregnated with water, to penetrate the matrix with hydrophilic resins while they eliminate water and simultaneously avoid collapse. During application, solvents repell interfibrillar water and evaporate together with water, leaving behind a monomer rich composition avoiding collagen collapse.

Residual or bound water is considered as structural water needed to prevent the interfibrillar collagen from collapsing while the resin infiltrates the matrix [4]. Water bound to collagen resists drying or solvent leaching by ethanol or acetone. According to K A. Agee, et al. bound water in dentin only represents $21-25 \%$ of total dentin water [5]. Remaining water is considered free water that solvents try to eliminate in clinically pertinent times $(30$ to $60 \mathrm{sec}$ ) to minimize phase separations.

When demineralized dentin is air dried, water contained in the interfibrillar spaces is removed and the collagen fibril network collapses, creating a shrunk network reinforced by interpeptide bonds, practically impermeable to adhesive resins. Moreover, the desiccation decreases the wettability of the dentin surface.

We speculate that the deficit in water of the dentin substrate associated with its very hydrophilic character entail an absorption of the water of the adhesive solution by the underlying dentin, decreasing the action of the acid and thus the depth of demineralization.

Under conditions of excessive moisture, the semi-permeable membrane properties, already highlighted by several studies, are

${ }^{*}$ Correspondence to: Geneviève Grégoire, Faculté de Chirurgie Dentaire, 3 chemin des Maraîchers Toulouse, France, Tel: +33 (0)5 621729 29; E-mail: genevieve.gregoire@univ-tlse3.fr

Key words: adhesive dentistry, dentin moisture, technique sensitivity, permeability, isopropanol

Received: November 20, 2019; Accepted: December 16, 2019; Published: December 19, 2019 
exacerbated, with the formation of droplets and water blisters. Depending on the adhesive used, these droplets have different localizations with reference to the adhesive layer, different sizes and different behaviors. The origin of these inclusions of water is attributed to a phase separation reaction. These droplets result from water attraction, diffusion of water and osmosis through the cured adhesive layer. These droplets are situated only at the resin composite boundary, a zone which corresponds to the oxygen-inhibition layer, a hypertonic area. Whatever their origin, these droplets reduce the thickness of the layer of resin and provide real spaces for the passage of water between the underlying dentin and the adhesive/composite interface [6].

Because stable long term adhesion is sought and interfacial water is needed, the aim of this study was to compare the technique sensitivity of an adhesive system to the moisture conditions of the dentinal substrate by measuring the dentin permeability variation [6-15]. Our working hypothesis was that the moisture conditions of the dentinal substrate have no influence on the technique sensitivity of the adhesive system tested.

\section{Materials and methods}

The dentinal variation due to the bonding system Prime \& Bond active (DENTSPLY DE TREY) was studied on moist and over dried dentin. The composition of the adhesive system used is given in Table 1 .

\section{Dentinal permeability variation $[6,8,15-18]$}

The change in dentinal permeability obtained after application of adhesive was evaluated by measuring the hydraulic conductance.

The bonding system was tested after application to either moist or overdry dentin substrate.

Hydraulic conductance is defined as the volume of fluid passing through a known surface area per unit time under a constant pressure gradient. A fluid pressure on a given surface induces a value of dentinal flow. In the present study, it was measured by the Flodec system (De Marco Engineering, Geneva, Switzerland) connected to a computer.

The fluid flow through a dentin slice was evaluated by the passage of physiological saline solution under a pressure of $200 \mathrm{~cm} \mathrm{H}_{2} \mathrm{O}$ over a surface $0.28 \mathrm{~cm}^{2}$ in area. Under this pressure, the liquid flowed in a conduit to a sample holder containing the dentin slice. Opposite the Flodec system, the fluid flowed through a calibrated capillary tube having a length of $310 \mathrm{~mm}$ and a total volume of $1 \mathrm{ml}$. An air bubble was incorporated in the capillary tube and its displacement was followed and measured by an optical sensor. Every 30 seconds, the Flodec system transmitted the distance covered by the bubble in this time interval to the computer. The linear movement of the bubble within the capillary tube was directly proportional to the fluid volume flowing through the dentin slice. This volume was given by the formula: Volume $(\mu \mathrm{l})=$ distance $(\mathrm{mm}) \times 1000(\mu \mathrm{l}) / 310(\mathrm{~mm})$.

Thus, a distance of $1 \mathrm{~mm}$ covered by the bubble in the capillary tube corresponded to a volume of $3.2 \mu \mathrm{l}$ passing through the dentin

Table 1. Composition of the tested adhesive systems

\begin{tabular}{|l|l|l|}
\hline Adhesive systems & Composition & Batch number \\
\hline Prime \& Bond active & $\begin{array}{l}\text { Phosphoric acid modified acrylate resin } \\
\text { Multifunctional acrylate }\end{array}$ & \\
DENTSPLY DE TREY & $\begin{array}{l}\text { Bifunctional acrylate } \\
\text { Acidic acrylate }\end{array}$ & \\
GmbH, Konstanz, & Isopropanol & 1506004120 \\
Germany & Water & \\
& Initiator & \\
& Stabilizer & \\
\hline
\end{tabular}

slice. The linear movement of the bubble is converted into hydraulic conductance by the formula: $\mathrm{Lp}=\mathrm{Jv} /$ (A. $\Delta$ P.t) [where $\mathrm{Lp}$ is the hydraulic conductance in $\mu \mathrm{l} \cdot \mathrm{cm}^{-2} \cdot \mathrm{min}^{-1} \cdot \mathrm{cmH}_{2} \mathrm{O}^{-1}$, Jv is the fluid flow in $\mu \mathrm{l}$, A is the dentin surface area in $\mathrm{cm}^{2}, \Delta \mathrm{P}$ is the hydraulic pressure gradient in $\mathrm{cm}$ $\mathrm{H}_{2} \mathrm{O}$ and $\mathrm{t}$ is the time in minutes]

\section{Specimens preparation}

Twenty human molars were used for the study. They were healthy 3rd molars extracted for reasons of development pathology. No impacted teeth were included in the number.

After extraction, the teeth were kept in chloramine $\mathrm{T}$ solution at $4^{\circ} \mathrm{C}$ until use.

A dentin slice $1 \mathrm{~mm}$ thick was obtained from each tooth by sawing the crown between the enamel and the top of the pulp chamber with cuts parallel to the occlusal surface, using a slow speed saw (Isomet 2000; Buehler, Evanston, Ill.) equipped with a rotating diamondimpregnated copper disk (Buehler).

The dentin specimens were considered to represent deep dentin where the number and diameter of dentinal tubuli increased. Deep dentin was chosen to favour the adhesive system infiltration into the demineralized dentin, an ideal condition for evaluating resin-dentin interaction mechanisms.

The dentin slices were etched on their occlusal and pulpal sides for 15 seconds with 36\% phosphoric acid (DE TREY Conditioner 36, DENTSPLY DE TREY GmbH, Konstanz, Germany) to remove the smear layer formed during sawing, then rinsed for 30 seconds. The etched dentin slices were then centred on a polycarbonate disk with a 6 $\mathrm{mm}$ diameter hole and glued on the pulpal side using epoxy glue. The assembled elements were dried for $24 \mathrm{~h}$ before testing.

The 20 dentin specimens were randomly divided into 2 groups of 10 , one subgroup for each use of the adhesive: moist or overdry dentin. $\rightarrow$ group 1: adhesive system Prime\&Bond active used on moist dentin $\rightarrow$ group 2: adhesive system Prime\&Bond active used on overdry dentin

The technique compared the hydraulic conductance before and after introduction of the adhesive system. The application of the adhesive system closed off part of the dentinal tubuli, resulting in a greater or lesser decrease of the initial permeability of the dentin, depending on the level of sealing due to the bonding adhesive: the higher the permeability, the lower the sealing effect. Every untreated specimen of dentin has a different permeability, depending on many factors (patient's age, number and diameter of the tubuli, mineralization, etc), so all subsequent permeability measurements made on the same specimen were expressed as a percentage increase or decrease with respect to the initial hydraulic conductance of the untreated specimen. Thus, each specimen served as its own control. The change in dentinal permeability obtained after application of adhesive to moist or overdry dentin was evaluated by measuring the hydraulic conductance.

\section{Measurement of specimen permeability after application of the adhesive in the two modes (moist or overdry)}

The initial hydraulic conductance through the slice of dentin was evaluated by measuring the passage of physiological saline. An experimental, standardized smear layer was produced on the occlusal surface of each specimen by means of 50 consecutive abrasions executed by manually moving very fine grained sandpaper (P4000; Buehler) horizontally and without vertical force under water irrigation. For the 
2 groups, the hydraulic conductance was measured again after this experimental abrasion, at time T0. The smear layer was etched (system using separate etching steps and rinsing), with an etching gel (DE TREY Conditioner 36, DENTSPLY DE TREY GmbH, Konstanz, Germany) and the hydraulic conductance of the specimens was measured again, at time T1.

For the group 1 (moist dentin), the dentin slides received $10 \mu \mathrm{l}$ of water, then the excess water was removed with cotton pellets but without overdrying the dentin. For the group 2 (overdry dentin), water was completely removed by air blown for 5 seconds at a distance of $7 \mathrm{~cm}$. Then, the adhesive system was placed according to the manufacturer's instructions (Table 2). The bonding system was in a single layer. The hydraulic conductance was measured for all specimens after application, at time T2.

The statistical analysis comprised an analysis of the mean and standard deviation for each test group, and an analysis of variance considering the T2 measurements as repeated measurements on a given specimen, and a multiple comparison test (Duncan's test) where the significance level was fixed at 0.05 .

The lamp used for photopolymerization was a SmartLite (Dentsply) having a light intensity of about $1200 \mathrm{~mW} / \mathrm{cm}^{2}$. The intensity of the lamp was measured before and after each utilization with a Curing Lightmeter 105 (Rolence Enterprise, Taiwan).

The measurements obtained before and after use showed no difference: the light intensity was about $1100 \mathrm{~mW} / \mathrm{cm}^{2}$.

\section{pH measurement $[19,20]$}

The $\mathrm{pH}$ of the adhesive system was measured with a model 210 microprocessor $\mathrm{pH}$ meter (Hanna Instruments, Woonsocket, Rhode Island, USA).

\section{Infrared spectroscopy}

Dentin was used here in powder form. Dentin powder was prepared as described previously [21]. Briefly, the crowns were removed from the roots, the pulp removed and the enamel carefully eliminated with a diamond burr under water irrigation. Dentin blocks were ground at low temperature in a grinder (K Janke \& Kunkel Ika ${ }^{\oplus}$, Labortechnik, Wasserburg, Germany) by adding nitrogen into the grinding chamber. The resulting dentin powder was sieved to obtain a powder with an average particle size of maximum $0.67 \mu$ mand then stored in the absence of moisture [22]. The powder was previously etched by adding $35 \%$ phosphoric acid for $15 \mathrm{sec}$. Following etching, the powder was rinsed with water and dried without overdrying as recommended for the wet-bonding technique. This etched powder was divided into 2 lots: one, where the dentin had been made too wet by adding $20 \mu \mathrm{l}$ of water for $100 \mathrm{mg}$ of powder before the adhesive, the other, where the dentin had been made dry by blotting before the adhesive.

IR spectra were taken for pure adhesive, and for adhesive applied on dentin powder, dried or humid, from 600 to $4000 \mathrm{~cm}^{-1}$ with a Perkin Elmer diamond spectrometer model ATR 2.

Table 2. Manufacturer's instructions for use of adhesive system tested

\begin{tabular}{|c|c|}
\hline Adhesive system & Manufacturer's instructions \\
\hline Prime \& Bond active & $\begin{array}{l}\text { - Use an applicator tip to apply adhesive to completely wet the } \\
\text { surfaces to be treated. Keep the adhesive slightly agitated for } 20 \\
\text { seconds. } \\
\text { - Disperse adhesive and remove solvent with clean, dry air. Treat } \\
\text { every surface with a moderate air flow for at least } 5 \text { seconds until } \\
\text { a glossy and uniform layer results. } \\
\text { - Cure adhesive for } 10 \text { seconds when using a curing light that has a } \\
\text { minimum irradiance of } 800 \mathrm{~mW} / \mathrm{cm}^{2} \text {. }\end{array}$ \\
\hline
\end{tabular}

Four IR spectra were recorded: dentin powder with no adhesive; Prime\&Bond active ahesive alone; Prime \& Bond active on humid dentin; Prime \& Bond active on dry dentin.

\section{Thermal analysis}

For analysis of bound or free water, etched dentin powder was divided in two parts and treated as described previously, to obtain a wet or dry dentin. One drop of adhesive was placed on each dentin aliquot (wet or dry) and then introduced in the Al sample holder. DSC analysis was performed with a Setaram analyzer scanning from -20 à $300^{\circ} \mathrm{C}$ at a rate of $10^{\circ} \mathrm{C} / \mathrm{min}$ with $10 \mathrm{mg}$ samples under a flow of nitrogen gas.

\section{Results}

\section{Dentinal permeability variation}

For each sample, the means calculated at each step (smear layer formation, etching and adhesive application) were compared with the mean of the initial hydraulic conductance to show the decrease or increase in dentinal permeability.

This study compared the dentinal permeabilities obtained after application of the adhesive used, with etching, on moist or overdry dentin.

The results of the study are reported in Table 3.

\section{Statistical study}

The comparison of the two modes of application used in this study (on moist or overdry dentin) and the Duncan's new multiple range test showed that the difference obtained with Prime\&Bond active was not significant $(\mathrm{p}=0.1867>0.05)$, so, used on moist or overdry dentin, this adhesive showed a single group: group a.

\section{1. pH measurement}

The $\mathrm{pH}$ of the tested adhesive gave a value of 2.63 .

\section{Infrared spectroscopy}

The infrared spectrum of dentin powder (a) showed a strong phosphate band at $1009 \mathrm{~cm}^{-1}$, carbonate vibrations at $1417 \mathrm{~cm}^{-1}$ and $\mathrm{OH}-\mathrm{H}$ at $3297 \mathrm{~cm}^{-1}$ (Figure 1).

The adhesive spectrum (b) showed peaks near $1700 \mathrm{~cm}-1(\mathrm{C}=\mathrm{O})$ and $1400 \mathrm{~cm}^{-1}(\mathrm{C}=\mathrm{C})$ related to the acrylate functional group, $\mathrm{C}-\mathrm{H}$ stretching vibrations near $2900 \mathrm{~cm}^{-1}$, and the presence of a band around $3400 \mathrm{~cm}^{-1}$ corresponding to the $\mathrm{O}-\mathrm{H}$ bond of the isopropanol solvent but also the water solvent.

For the adhesive on dentin ( $c$ and $d$ ), the dentin components were covered by the organic components. In the case of adhesive on wet dentin (c) and dry dentin (d) the ratio of peak intensities for water compared to acrylate was twice as large for wet vs dry dentin.

\section{Thermal analysis}

The results obtained by DSC were illustrated in figure 2. For the wet dentin (a), these results showed a small endothermal peak near $0^{\circ} \mathrm{C}$ and another less resolved peak near $100^{\circ} \mathrm{C}$. Such endothermal peaks correspond to frozen water melting at $0^{\circ} \mathrm{C}$ and evaporating at $100^{\circ} \mathrm{C}$. The other endotherms correspond to collagen melting near $130^{\circ} \mathrm{C}$, and are followed by an exotherm related to organic matter decomposition near $200^{\circ} \mathrm{C}$. When the dentin is dry (b), we could notice the absence of the endothermic peak of the water $\left(0^{\circ} \mathrm{C}\right)$. 
Table 3. Means and standard deviations of test specimen permeability following surface treatment and bonding agent used, with etching, on moist or overdry dentin (expressed in percentage decrease or increase with respect to baseline value)

\begin{tabular}{|l|c|c|c|}
\hline Adhesive system & Dentin & T0 & T2 Post-Adhesive \\
\hline \multirow{2}{*}{ Prime \& Bond active } & wet & $27.5 \%+/-14.6$ & $51.2 \%+/-9.9$ \\
\cline { 2 - 4 } & overdry & $28.3 \%+/-8.6$ & $45.8 \%+/-7.6$ \\
\hline
\end{tabular}

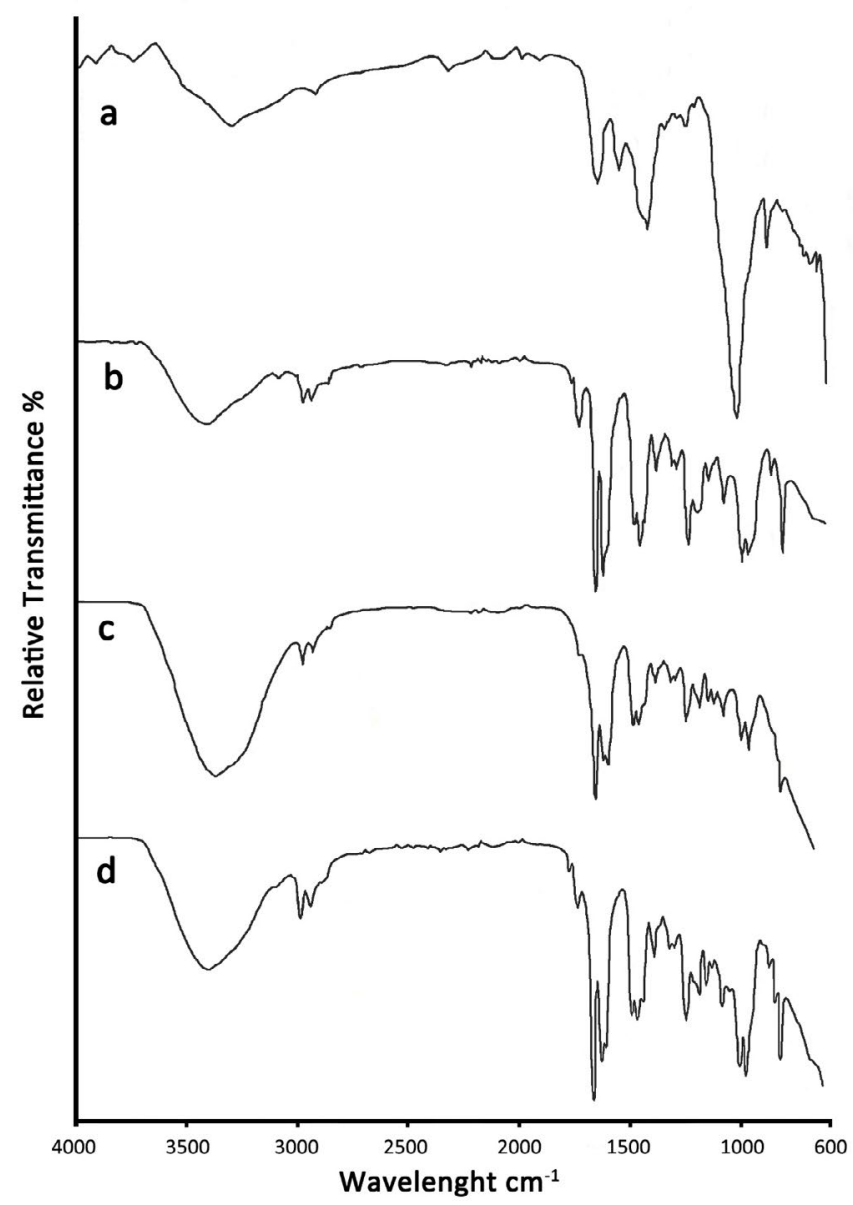

Figure 1. Infrared spectra of dentin powder (a), adhesive (b), adhesive on wet dentin (c) and dry dentin (d)

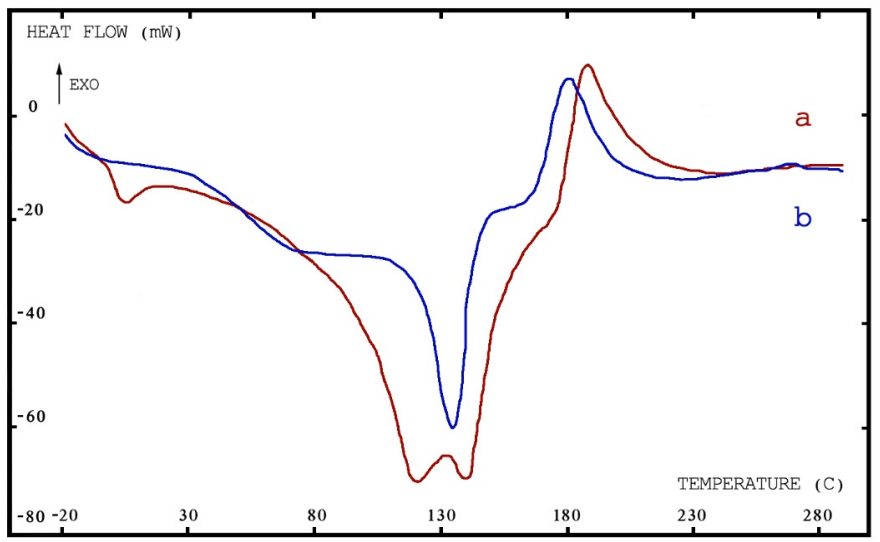

Figure 2. Thermogravimetric analysis of adhesive on wet dentin (a) and dry dentin (b). Exothermal phenomena are upwards and endothermal downwards

\section{Discussion}

Results presented with adhesives containing isopropanol are comparable to previously presented ones [6-8]. The low molecular weight components (water and isopropanol) are first to melt and evaporate simultaneously with low exothermicity (judging by the endotherm with small surface area at $0^{\circ} \mathrm{C}$ ) and this is followed by a sluggish collagen denaturation near $80^{\circ} \mathrm{C}$ and more sharp melting at $130^{\circ} \mathrm{C}$. The DSC results are in line with the IR spectra showing more intense $\mathrm{O}-\mathrm{H}$ vibrations for humid dentin, and smaller vibrations when dentin is dry. Hydrogen bonded $\mathrm{OH}$ groups tend to shift to lower, less energetic wavelengths (shoulder near $3200 \mathrm{~cm}^{-1}$ ). For in depth monomer penetration to take place, a hydrophilic network is needed with hydrated tubules fully opened [23]. Thus isopropanol containing adhesive may be adequate for bonding to wet and/or dry dentin surfaces.

\section{Conclusion}

Within the limitations of this study and with the results of all the other adhesives tested in our laboratory under identical conditions, the adhesive didn't yield unfavourable results, whether the technique was moist or overdry. The results point to the use of solvent with favourable solubilities and vapour pressure compatible with adhesive resins [24]. Our working hypothesis was verified because the moisture conditions of the dentinal substrate have no influence on the technique sensitivity of the adhesive system tested.

\section{Conflicts of interest statement}

No conflicts of interest.

\section{References}

1. Grégoire G, Akon B, Millas A (2002) Interfacial micromorphological differences in hybrid layer formation between water and solvent-based dentin bonding systems. $J$ Prosthet Dent 87: 633-641. [Crossref]

2. Ferrari M, Tay FR (2003) Technique sensitivity in bonding to vital, acid-etched dentin Oper Dent 28: 3-8. [Crossref]

3. Klein-Junior CA, Zander-Grande C, Amaral R, Stanislawczuk R, Garcia EG, et al (2008) Evaporating solvents with a warm air-stream: effects on adhesive layer properties and resin-dentin bond strengths. $J$ Dent 36: 618-625. [Crossref]

4. Fullerton GD, Amurao MR (2006) Evidence that collagen andtendon have monolayer water coverage in the native state. Cell Biol Int 30: 56-65. [Crossref]

5. Agee KA, Prakki A, Abu-Haimed T, Naguib GH, Nawareg MA, et al. (2015) Water distribution in dentin matrices: Bound vs. unbound water. Dent Mater 31: 205-216. [Crossref]

6. Grégoire G, Guignes P, Nasr K (2009) Effects of dentin moisture on the permeability of total-etchand self-etch adhesives. J Dent 37: 691-699. [Crossref]

7. Grégoire G, Dabsie F, Dieng-Sarr F, Sharrock P (2011) Solvent composition of onestep self-etch adhesives and dentin wettability. J Dent 39: 30-39. [Crossref]

8. Grégoire G, Sharrock P, Prigent Y (2016) Performance of a universal adhesive on etched and non-etched surfaces: Do the results match the expectations? Mater Sci Eng C Mater Biol App 66: 199-205. [Crossref]

9. Grégoire G, Sharrock P, Delannée M, Delisle M-B (2013) Depletion of water molecules during ethanol wet-bonding with etch and rinse dental adhesives. Material Science and Engineering 33: 21-27.

10. Chiba A, Zhou J, Nakajima M, Tan J, Tagami J, et al. (2016) The effects of ethanol on the size-exclusion characteristics of type I dentin collagen to adhesive resin monomers. Acta Biomater 33: 235-241. [Crossref]

11. Jee SE, Zhou J, Tan J, Breschi L, Tay FR, et al. (2016) Investigation of ethanol infiltration into demineralized dentin collagen fibrils using molecular dynamics simulations. Acta Biomater 36: 175-185. [Crossref] 
12. Reis AF, Arrais CA, Novaes PD, Carvalho RM, De Goes MF, et al. (2004) Ultramorphological analysis of resin-dentin interfaces produced with water-based single-step and two-step adhesives: nanoleakage expression. J Biomed Mater Res B Appl Biomater 71: 90-98. [Crossref]

13. Hosaka K, Nishitani Y, Tagami J, Yoshiyama M, Brackett WW, et al. (2009) Durability of resin-dentin bonds to water- vs. ethanol-saturated dentin. $J$ Dent Res 88: 146-151. [Crossref]

14. Manso AP, Marquezini L Jr, Silva SM, Pashley DH, Tay FR, et al. (2008) Stability of wet versus dry bonding with different solvent-based adhesives. Dent Mater 24: 476482. [Crossref]

15. Nishitani Y, Yoshiyama M, Donnelly AM, Agee KA, Sword J, et al. (2006) Effects of resin hydrophilicity on dentin bond strength. J Dent Res 85: 1016-1021. [Crossref]

16. Grégoire G, Joniot S, Guignes P, Millas A (2003) Dentin permeability : self-etching and one-bottle dentin bonding systems. J Prosthet Dent 90: 42-49. [Crossref]

17. Grégoire G, Guignes P, Millas A (2005) Effect of self-etching adhesives on dentin permeability in a fluid flow model. J Prosthet Dent 93: 56-63. [Crossref]

18. Grégoire G, Dabsie F, Delannée M, Akon B, Sharrock P (2010) Water permeability, hybrid layer long-term integrity and reaction mechanism of a two-step adhesive system. $J$ Dent 38: 526-533. [Crossref]
19. Delannée M, Grégoire G, Vergnes JN, Sharrock P (2013) Fluid flow through dentineself-etch resin interface during long term in vitro aging. Mater Sci Eng C Mater Biol Appl 33: 3711-3715.

20. Grégoire G, Millas A (2005) Microscopic evaluation of dentin interface obtained with 10 contemporary self-etching systems: correlation with their $\mathrm{pH}$. Oper Dent 30: 481491. [Crossref]

21. Mazzoni A, Pashley DH, Nishitani Y, Breschi L, Mannello F, et al. (2006) Reactivation of inactivated endogenous proteolytic activities in phosphoric acid-etched dentine by etch-and-rinse adhesives. Biomaterials 27: 4470-4476. [Crossref]

22. Elfersi S, Grégoire G, Sharrock P (2002) Characterization of sound human dentin particles of sub-millimeter size. Dent Mater 18: 529-534. [Crossref]

23. Grégoire G, Sharrock P, Lacomblet MP, Tavernier B, Destruhaut F (2019) Evaluation of a self-etch primer containing acrylophosphonic acid and HEMA monomers on human dentin. Oral Health and Care 4: 2-7.

24. Sartori N, Peruchi LD, Phark JH, Lopes MM, Araújo É, et al. (2015) Permeation of intrinsic water into ethanol- and water-saturated, monomer-infiltrated dentin bond interfaces. Dent Mater 31: 1385-1395.

25. Irmak Ö, Baltacıŏlu İH, Ulusoy N, Bağış YH (2016) Solvent type influences bond strength to air or blot-dried dentin. BMC Oral Health 16: 77. [Crossref]

Copyright: (2019 Grégoire G. This is an open-access article distributed under the terms of the Creative Commons Attribution License, which permits unrestricted use, distribution, and reproduction in any medium, provided the original author and source are credited. 